\title{
Familial Hodgkin's disease
}

\author{
P. J. Hull \\ M.R.C.P.
}

\author{
I. W. Delamore \\ Ph.D., F.R.C.P., F.R.C.Path.
}

University Department of Clinical Haematology, Royal Infirmary, Manchester M13 9WL

\begin{abstract}
Summary
A family with Hodgkin's disease is described. Each affected member of the family had mediastinal involvement and in each case the histology was that of nodular sclerosing Hodgkin's disease. The significance of these findings with reference to the aetiology of the disease is discussed.
\end{abstract}

\section{Introduction}

Recent reports suggesting that Hodgkin's disease may be transmitted from person to person, particularly in those under 45 years of age (Vianna, Greenwald and Davies, 1971; Vianna et al., 1972; Vianna and Polan, 1973; Evans et al., 1977) have given added interest to familial clustering of the disease. Forty-six cases of familial Hodgkin's disease have so far been reported in the world literature. In this paper a further family is reported in whom a brother, sister and cousin were affected. All were under the age of 45 years and all had mediastinal involvement.

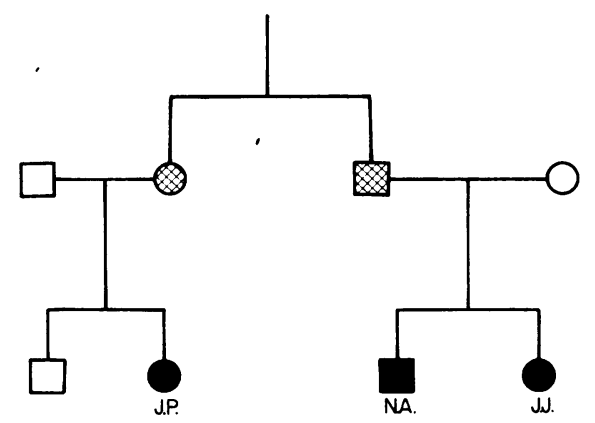

Fig. 1. Family tree. $\bigcirc$ unaffected female; affected female; $\square$ unaffected male; $\square$ affected male; hatched symbols - unaffected parental siblings.

\section{Case reports}

Case 1

N.A. is a 23-year-old male language graduate who presented in 1976 with a 4-month history of malaise, weight-loss and night sweats. On examination, apart from a mild intermittent pyrexia of $37-38^{\circ} \mathrm{C}$ and a palpable supraclavicular node, there were no abnormal physical signs. Investigation showed ait elevated ESR of $25 \mathrm{~mm}$ in the first hour, a norma $\vec{\psi}$ full blood count and normal liver function testso The chest X-ray showed a large anterior mediastinas mass associated with para-tracheal nodes. The supraclavicular node was biopsied and nodulap sclerosing Hodgkin's disease was diagnosed. ThE patient underwent a staging laparotomy, but no further evidence of Hodgkin's disease was found. He was subsequently treated with mantle deep X-rabs therapy to a total dose of $3500 \mathrm{rad}$ plus anterior mediastinal irradiation of $600 \mathrm{rad}$. This was followed by chemotherapy in the form of mustine hydroe chloride $10 \mathrm{mg}$ i.v. on day 1 , together with vinblastine $10 \mathrm{mg}$ i.v. on day 1 , procarbazine $50 \mathrm{mg}$ three times $\mathbb{P}$ day by mouth on days $1-14$, and prednisolone 40 $\mathrm{mg} /$ day by mouth on days 1-14 (MVPP). Tis course was repeated every 6 weeks to a total of courses after complete remission. One month afep radiotherapy a chest X-ray showed completes resolution of the mediastinal mass and there has been no recurrence to date (Aug. 1977).

\section{Case 2}

J.J. is a 22-year-old housewife who is a sister of N.A. and was admitted to hospital in 1970 with paraparesis. For 2 years before admission she had. complained of pain in the upper thoracic region which was made worse by drinking alcohol. On examination, she had a spastic paraparesis with as sensory level at the sixth thoracic dermatome. There was a large palpable lymph node in the left axilla응 A chest X-ray showed her to have mediastina glandular enlargement and X-ray of the thoracic spine showed the vertebral bodies of T5 and T6 to 8 be partially collapsed. A myelogram demonstrated a block at the level of T4. She underwent surgeryN during which the spinal column was exposed and the bone and epidural space was found to be extensivelyo infiltrated by tumour. Biopsy of this tumour showedw nodular sclerosing Hodgkin's disease. She was treated with MVPP and made a complete recoveryo She now has no neurological deficit and is able tod play tennis and take part in all normal activities:? Five courses of treatment in all were administered 00 She has remained well to date (1977). 
Case 3

J.P. is a 13-year-old schoolgirl who is a first cousin of N.A. and J.J. She was admitted to hospital in 1969 with a 12-month history of lassitude, pruritus and recurrent pyrexia. She had also complained of some weakness in the left leg. On examination she had palpable lymph nodes in the right axilla and the right supraclavicular fossa. There was no enlargement of liver or spleen. She had a normal blood count, but the ESR was elevated at $71 \mathrm{~mm}$ in the first hour. The chest X-ray showed superior mediastinal glandular enlargement with some associated enlargement of the hilar glands. Gland biopsy confirmed the diagnosis of nodular sclerosing Hodgkin's disease. She was treated with deep X-ray therapy to the mediastinum and to the glands in the right and left axilla. This was followed by cyclophosphamide as single agent chemotherapy. In 1974 she relapsed and was treated with a variety of drugs including C-MOPP (cyclophosphamide, vincristine, procarbazine and prednisolone) and subsequently CCNU and procarbazine. Unfortunately this disease has still not remitted and she is currently receiving treatment with chlorambucil for persistent disease.

\section{Discussion}

In a recent incidence survey of Hodgkin's disease, Grufferman et al. (1977) in greater Boston found that siblings of young adults with Hodgkin's disease had about a seven-fold excess risk of contracting the disease. Of the forty-six cases in the literature thirty were sex-concordant; the present cases, therefore, were somewhat unusual. They estimated that siblings of the same sex as an affected person have a risk about double that of siblings of the opposite sex, and they point out that if the spread to siblings was by an infectious agent all siblings should have similar risks. Rather intense or prolonged contact seems necessary to transmit any agent. Another possible explanation is a common source of exposure. Genetic mechanism such as the increased susceptibility of patients with certain genotypes (Zervas, Delamore and Israëls, 1973) may be a factor, but it would not explain sexconcordance.

Nodular sclerosis seems to be the most common form likely to be associated with familial Hodgkin's disease and it may be that this is the most common form caused by an infectious agent (Cole, McMahon and Aisenberg, 1968). It is interesting that all three cases reported here had the nodular sclerosing histological type and all had mediastinal involvement.

There appears to be no increased risk of familial involvement over the age of $\mathbf{4 5}$ years and this may reflect a different aetiology in the older age groups (McMahon, 1966).

\section{Acknowledgments}

We are grateful to Dr A. M. Jelliffe, Middlesex Hospital, London, for permission to publish case J.P. We would also like to thank Dr I. Todd, Christie Hospital, Manchester, for supplying details of radiotherapy.

\section{References}

Cole, P., McMahon, B. \& Aisenberg, A. (1968) Mortality from Hodgkin's disease in the U.S.A. Evidence for the multiple aetiology hypothesis. Lancet, ii, 1371.

Evans, A.R., Hancock, B.W., Brown, M.J. \& Richmond, J. (1977) A small cluster of Hodgkin's disease. British Medical Journal, 1, 1056.

Grufferman, S., Cole, P., Smith, P.G. \& Lukes, R.J. (1977) Hodgkin's disease in siblings. New England Journal of Medicine, 296, 248.

McMahon, B. (1966) Epidemiology of Hodgkin's disease. Cancer Research, 26, 1189.

Vianna, N.J., Greenwald, P., Brady, J., Polan, A.K., DWorK, A., MAURo, J. \& DAvies, J.N.P. (1972) Hodgkin's disease: cases with features of a community outbreak. Annals of Internal Medicine, 77, 169.

Vianna, N.J., Greenwald, P. \& Davies, J.N.P. (1971) Extended epidemic of Hodgkin's disease in high-school students. Lancet, i, 1209.

Vianna, N.J. \& Polan, A.K. (1973) Epidemiologic evidence for transmission of Hodgkin's disease. New England Journal of Medicine, 289, 499.

Zervas, J.D., Delamore, I.W. \& Israëls, M.C.G. (1970) Leucocyte phenotypes in Hodgkin's disease. Lancet, ii, 634. 